\title{
Association Between Backfat Thickness at 28 Weeks Old and Production Traits of Primiparous Landrace Sows Raised Under Tropical Conditions
}

Praew Thiengpimol

Kasetsart University - Bangkhen Campus: Kasetsart University

Skorn Koonawootrittriron

Kasetsart University - Bangkhen Campus: Kasetsart University

Thanathip Suwanasopee ( $\sim$ agrtts@ku.ac.th )

Kasetsart University https://orcid.org/0000-0002-9707-6428

\section{Research Article}

Keywords: Replacement gilt, Correlation, Energy reserve, Body weight, Piglet loss

Posted Date: September 16th, 2021

DOI: https://doi.org/10.21203/rs.3.rs-803923/v1

License: (c) (i) This work is licensed under a Creative Commons Attribution 4.0 International License.

Read Full License 


\section{Abstract}

Backfat thickness could reflex energy reserve of the female pigs that is required for their productivity, especially gilts that might be selected for the replacements. Therefore, phenotypic and genetic correlations between backfat thickness (BF) and production traits were estimated and considered for the possibility of using BF at pre-selective stage as an early indicator for productivity of the sow. Pedigree information, BF and body weight (BW) at 28 weeks old, age at first farrowing (AFF), transformed proportion of piglet loss at birth (tPL) and transformed weaning to first service interval (tWSI) of 806 primiparous Landrace sows were used to estimate the variance components by restricted maximum likelihood procedure with an average information algorithm for multivariate analysis. Genetic correlation between BF and BW was $0.70 \pm 0.13$. Both BF and BW had negative genetic correlation with AFF, but not tWSI. Unfortunately, genetic correlation estimates between $\mathrm{PL}$ and other traits was unclear due to high standard error. The genetic correlation between AFF and tWSI was $0.78 \pm 0.36$. Besides $19.35 \%$ of sires, $26.34 \%$ of dams and $25.81 \%$ of sows had genetic ability for BF, BW, AFF and WSI above the population means. The genetic association between BF, BW, AFF and tWSI indicated the feasibility of using selection index to improve BF and BW at pre-selective stage and reduce AFF and tWSI of replacement gilt simultaneously. However, the estimation of genetic correlation between PL and other traits should be repeated in a larger population.

\section{Introduction}

Replacement gilt is a key factor for determining the productivity of sows in commercial pig production. Before entering the breeding herd, age and body weight of gilt are considered as the final criteria for maturity of the replacement. However, gilt's body condition that accounts for both body weight and backfat thickness should be focused on, not only body weight (Eastwood and Smith 2020). Recently, backfat thickness can be easily measured in real-time by an ultrasonic probe which is the convenient and accurate method to assess body condition, compared to visual scoring and individual weighting. It can reflex the amount of energy reserve of the female pig that is necessary for fertility, maintaining pregnancy, embryonic and fetal developments, mammary tissue growth, milk production, rearing the newborn piglets and preventing weight loss during lactation period (Kyriazakis and Whittemore 2006). Particularly for gilts which are prone to mobilize body reserves (Houde et al. 2010) because they also need the energy for their growth to become mature (Kemp et al. 2018). Thus, it is important that gilts should have an adequate fat stored in their body at the starting life to optimize their subsequent productive performance (Kyriazakis and Whittemore 2006).

Body weight is a production trait for commercial pig production. It could reflect growth potential and body maturity (PIC North America, 2015). Besides, large gilt may have great piglet productivity due to a larger uterine capacity, heavier uterine weight and longer uterine length that is required for fetal development (Kyriazakis and Whittemore 2006; Tummaruk and Kesdangsakonwut 2014). In a breeding herd, delayed puberty, high percentage of dead piglets at birth and prolonged weaning to first service interval have been documented as a crucial negative effect on farm profitability. These production traits should be 
considered in genetic improvement program for the replacement, especially in a tropical region that high ambient temperature could lead to heat stress which is well known as the stimulator for poor reproductive efficiency of sow by causing delayed puberty, increased embryonic mortality, and extended weaned to estrus interval (Kraeling and Webel 2015). Unfortunately, an association between backfat thickness and production traits of sows have mostly been studied in term of phenotype (Bečková et al. 2005; Tummaruk et al. 2007; Houde et al. 2010; Roongsitthichai et al. 2010; Flisar et al. 2012; Lavery et al. 2019; Lego and Bondoc 2020) that could not be used efficiently for genetic improvement program. There have been a few reports on genetic correlations between backfat thickness with growth rate (Imboonta et al. 2007; Wongsakajornkit and Imboonta 2015; Alam et al. 2021), particularly litter traits (Holm et al. 2004; Arango et al. 2005; Imboonta et al. 2007) and weaning to first service interval (Holm et al. 2004). In case of piglet loss at birth, it was studied by considering number of stillborn piglets and number of piglets dead within 24 hours of birth (Arango et al. 2005; Imboonta et al. 2007) without counting for mummified piglets in the litter that partly involves the economic loss for the farm. The proportion of piglet loss at birth that accounts for both mummified and stillborn piglets could be an alternative trait for improving the production of sows (Thiengpimol et al. 2020) but its genetic association with backfat thickness of gilt has not been reported.

Landrace is well known as the dam line for commercial pig production. They have been imported and selected under tropical environment in Thailand over two decades and it might be similar in other tropical countries. The study of backfat thickness at pre-selection stage of Landrace raised under tropical condition and its association with economic production traits has been limited. Therefore, this research aimed to estimate phenotypic and genetic correlations between backfat thickness and body weight, age at first farrowing, proportion of piglet loss at birth and weaning to first service interval in primiparous Landrace sow population raised under tropical condition. The result would indicate the possibility of using backfat thickness of gilt at pre-selective stage as an early indicator for improving subsequent productive performance in tropical environment.

\section{Materials And Methods}

\section{Population, data collection and traits}

Field data were collected from 806 selected Landrace sows in a commercial pig farm in Northern Thailand (latitude $18^{\circ} 47^{\prime} 43^{\prime \prime}$ North; longitude $98^{\circ} 59^{\prime} 55^{\prime \prime}$ East). According to the report of Thai Meteorological Department (2019), an average daily ambient temperature was $27^{\circ} \mathrm{C}$ with average daily minimum temperature of $22^{\circ} \mathrm{C}$, average daily maximum temperature of $33^{\circ} \mathrm{C}$ and average relative humidity of 70\%. These sows were born between July 2010 and December 2015 from 124 sires and 391 dams and gave first litter between July 2011 and January 2017.

The dataset consisted of pedigree information, backfat thickness (BF; mm) and body weight records at 28 weeks of age, and performance records at first parity. The pedigree information contained the identification of sow, their sire and dam, breed group and birthdate. The ultrasonic probe was applied to 
measure BF at 6 to $8 \mathrm{~cm}$ away from the dorsal midline at the last rib of replacement gilts. The individual gilt was weighted in $\mathrm{kg}$. The performance records of sow at first parity comprised identification of boar for artificial insemination, number of total born piglets, number of mummified piglets, number of stillborn piglets and number of weaned piglets. The date at body measuring, at farrowing, at weaned and at first service for the next production cycle were also recorded.

There were four production traits which included body weight at 28 weeks old (BW; kg), age at first farrowing (AFF; day), proportion of piglet loss at birth (PL; \%) and weaning to first service interval (WSI; day). For AFF, it was defined as the duration between date at birth and date at first farrowing. The PL was computed by summation of the number of mummified and stillborn piglets within a litter divided by the number of total born piglets, then multiplied by 100. Description of WSI was the number of days between date at weaned after first farrowing and date at first service in the next production cycle.

\section{Feeding and management}

All pigs were raised under the open-house system condition until October 2015, after that they have been reared in the evaporative cooling system to control temperature and humidity in the housing. At 30 to 32 weeks of age, replacement gilts were selected based on their body conformation, age, breed characteristics and health status. Gilts and non-lactating sows received concentrate feed with $16 \%$ crude protein (metabolizable energy; ME at 13,389 to $14,644 \mathrm{KJ}$ ) twice a day (07:00 and 13:00) in the amount of $2.5 \mathrm{~kg} /$ day. For lactating sow, the amount of 5 to $6 \mathrm{~kg} /$ day with 17 to $18 \%$ crude protein (ME at 16,987 $\mathrm{KJ})$ was provided four times a day (07:00, 10:00, 13:00 and 15:00).

In both replacement gilts and sows, signs of estrus were checked twice a day in the morning and afternoon by visual appraisal and boar exposure. Five days before the third estrus cycle, the replacement gilts were transferred into the individual stall for mating. After the onset of standing heat, they were artificially inseminated ( 12 hours after detected estrus and the next 12 hours after the first insemination with the same boar) for the first time at 8 to 9 months of age or at a body weight of $140 \mathrm{~kg}$. A week before the expected parturition date, pregnant gilts were moved into the farrowing pens and received good support during delivery. Cross-fostering was practiced within 24 hours after born. After that, the piglets were weaned and transferred into the nursery unit when they reached 5 to $7 \mathrm{~kg}$ of body weight or 26 to 30 days of age. While the sows were moved into the individual stall to prepare for the next production cycle.

\section{Descriptive statistical analysis}

All data were checked to remove the erroneous. Then, the complete dataset was used to test the hypothesis of the normal distribution for all traits which were BF, BW, AFF, PL and WSI. According to positive skewness (2.52 for PL; 2.45 for WSI), PL and WSI were transformed using natural logarithm before data analysis, then are called tPL $[\ln (P L+1)]$ and tWSI [In(WSI)]. Statistics (i.e., mean, standard deviation, minimum, maximum, and coefficient of variation) for productive performances of sows in this population were described. 


\section{Phenotypic and genetic correlations estimation}

The covariances and variance components for BF, BW, AFF, tPL and tWSI were estimated using average information algorithm by restricted maximum likelihood procedure (Gilmour et al. 2000) under multivariate analysis with four animal models. Year and season at birth, at farrowing and at weaned (depending on the trait) were concurrently considered, to categorize the contemporary group, which was covered the different period of rearing female pigs (open-house system and evaporative cooling system; before and after October 2015). Sows that were born in the same year-season were assumed to receive the similar feed, routine management, sanitary program, and environment. This assumption was also applied for sows that farrowed or weaned in the same year-season. Seasons were classified as winter (November to February), summer (March to June) and rainy (July to October).

In the animal model for BF and BW, year-season at birth (17 contemporary groups), and age at measuring (in day; covariate) were considered as fixed effects. For AFF, the fixed effect was year-season at birth (17 contemporary groups). For $\mathrm{tPL}$, fixed effects were year-season at farrowing (17 contemporary groups) and service boar ( 81 boars). For tWSI, fixed effects included year-season at weaned (17 contemporary groups) and number of weaned piglets (covariate). The random effects for these four animal models were animal and residual as the followed model; $y=X b+Z a+e$, where $y$ is the vector of observations for $B F, B W, A F F, t P L$ and tWSI, $b$ is the vector of fixed effects, $a$ is the vector of random animal additive genetic effect, $X$ and $Z$ are the incidence matrixes related to elements of vectors $b$ and $a$, respectively, and $\mathrm{e}$ is the vector of residual random effect. All random effects for study traits were assumed to be a normal distribution. The assumption of variance and covariance structure were given in the mixed model equation below.

$$
\left[\begin{array}{l}
\mathrm{y} \\
\mathrm{a} \\
\mathrm{e}
\end{array}\right] \sim M V N\left(\left[\begin{array}{c}
\mathrm{Xb} \\
0 \\
0
\end{array}\right],\left[\begin{array}{ccc}
\mathrm{ZGZ}+\mathrm{R} & \mathrm{ZG} & \mathrm{R} \\
\mathrm{GZ} & \mathrm{G} & 0 \\
\mathrm{R} & 0 & \mathrm{R}
\end{array}\right]\right)
$$

where $G$ is $G_{0} \otimes A$, where $G_{0}$ is a $5 \times 5$ matrix of genetic covariance among traits $(B F, B W, A F F, t P L$ and tWSI), $A$ is the numerator relationship matrix and $\otimes$ represents the direct product, $R$ is $R_{0} \otimes I$, where $R_{0}$ is a $5 \times 5$ matrix of residual covariance among traits (BF, BW, AFF, tPL and tWSI) and I is an identity matrix.

Estimated variances and covariances were used to calculate phenotypic and genetic correlations. The general linear models were used to test the significance of fixed effects on study traits. For TPL and tWSI, estimated means in each subclass of factors and estimated breeding values (EBV) of the animal were back transformed by taking exponential function. Then, the linear relationship between EBVs for BF and BW, AFF, PL and WSI were illustrated.

\section{Results}

\section{Distribution and descriptive statistics}


The BF at pre-selective stage (before entering the breeding herd) of Landrace gilts was distributed between 7 to $20 \mathrm{~mm}$ with an average of $12.17 \mathrm{~mm}$. Most of the gilt (78\%) had BF between 10 to $14 \mathrm{~mm}$

(Fig. 1a). Whereas the BW ranged from 77 to $146 \mathrm{~kg}$ with an average of $109.96 \mathrm{~kg}$. About $62 \%$ of gilts had BW ranged from 100 to $120 \mathrm{~kg}$ which has been required as a target weight for slaughter. At first farrowing, the sows were 411 days old on average, produced 10.94 piglets in total but lost $13.05 \%$ of them at birth (Table 1), presented as mummified piglets (4.98\%) and stillborn piglets (8.07\%). After weaned, they spent approximately 8 days to return to service with the mode of 5 days ( $36 \%$ of the population).

\section{Fixed effects}

The difference in routine management and environmental conditions in each contemporary group had significantly influenced on $\mathrm{BF}, \mathrm{BW}, \mathrm{AFF}(P<0.0001)$, tPL $(P=0.0046)$ and tWSI $(P=0.0002)$. The BF estimate of gilts varied from $10.59 \pm 0.67$ (winter 2013) to $14.20 \pm 0.68$ (summer 2014) mm along 5 years of birth. Since 2014, BF tended to slightly increase from 11.66 (average BF of gilts born in rainy 2010 to winter 2013) to 12.80 (average BF of gilts born in summer 2014 to winter 2015) $\mathrm{mm}$. In contrast, the selected gilts tended to be smaller if considered by BW. Gilts born in winter 2015 had a lighter weight $(-22.17 \pm$ $3.74 \mathrm{~kg}$ ) than gilts born in rainy 2010. Age at first farrowing seems to be changed adversely with gilt's BF. The turning point was at summer in 2014 where the BF increased from 10.59 to $14.20 \mathrm{~mm}$ while AFF decreased from 491 to 463 days and tended to be shorten since then. For tPL and tWSI, both traits fluctuated along the production period without critical points in a particular season of the year.

Age at measuring (varied from 182 to 211 days) had no significant impact on $\mathrm{BF}(P=0.0564)$ and $\mathrm{BW}$ $(P=0.0701)$. The coefficient estimates of age at measuring was $0.05 \pm 0.03$ for BF and $0.30 \pm 0.13$ for BW. The service boar was not a significant effect on $\operatorname{tPL}(P=0.3555)$. Although these sows had weaned piglets varied from 0 to 18 piglets, it did not relate to tWSI $(P=0.5434)$.

\section{Variances and covariances}

Phenotypic variations for BF and production traits associated with variation of environment more than genetic. The highest proportion of genetic variance was obtained for BW with heritability estimate of 0.47 \pm 0.08 , followed by BF, tWSI, AFF and tPL (Fig. 2). The phenotypic covariance was $11.96 \pm 1.10 \mathrm{~mm} \cdot \mathrm{kg}$ for $\mathrm{BF}$ and $\mathrm{BW},-11.59 \pm 2.30 \mathrm{~mm} \cdot \mathrm{day}$ for $\mathrm{BF}$ and $\mathrm{AFF},-0.02 \pm 0.13 \mathrm{~mm} \% \%$ for $\mathrm{BF}$ and $\mathrm{TPL}$ and $-0.01 \pm 0.04$ $\mathrm{mm} \cdot \mathrm{day}$ for $\mathrm{BF}$ and tWSI. Whereas the genetic covariance was $5.56 \pm 1.78 \mathrm{~mm} \cdot \mathrm{kg}$ for BF and $\mathrm{BW},-3.83 \pm$ $2.84 \mathrm{~mm} \cdot$ day for $\mathrm{BF}$ and $\mathrm{AFF}, 0.05 \pm 0.15 \mathrm{~mm} \%$ for $\mathrm{BF}$ and $\mathrm{tPL}$ and $0.00 \pm 0.04 \mathrm{~mm} \cdot$ day for $\mathrm{BF}$ and tWSI.

\section{Phenotypic and genetic correlations}

The BF positively correlated with BW in both phenotypic $(0.49 \pm 0.03)$ and genetic $(0.70 \pm 0.13)$ terms but had negative phenotypic $(-0.20 \pm 0.04)$ and genetic correlations $(-0.42 \pm 0.28)$ with AFF (Table 2$)$.

Phenotypic correlation between BF and TPL was close to zero but genetic correlation between both traits was positive. There was no correlation between BF and tWSI in both phenotypic and genetic terms. 
Both BF and BW had a negative genetic correlation with AFF. Their associations were also verified by EBV relationships in Fig. 3. Increased one mm of EBV for BF would associate with increased $7.54 \mathrm{~kg}$ of EBV for BW $(y=7.5437 x+0.0675)$ and reduced 5 days of EBV for AFF $(y=-4.9457 x-0.1541)$. Although the genetic correlation between BF and tPL was positive $(0.40 \pm 1.64)$, similar with BW and TPL $(0.78 \pm 2.60)$, their associations were not obviously revealed in this population due to high standard error of the estimates. According to the EBV relationship in Fig. 3c, a small response of PL to BF was indicated. Even EBV for BF increased $10 \mathrm{~mm}$, it might result in increasing EBV for PL only $0.9 \%(y=0.0895 x+0.003)$. Likewise, regression coefficient estimate of EBV for tWSI on BF (Fig. 3d) was close to zero ( $y=0.002 x+$ 1.0012). Fortunately, the genetic correlation between AFF and tWSI was high and positive $(0.78 \pm 0.36)$.

\section{Discussion}

\section{Variations of BF and production traits}

At pre-selective stage, difference between the thickest BF gilts $(20 \mathrm{~mm})$ and the lowest one $(7 \mathrm{~mm})$ was almost three times (range $13 \mathrm{~mm}$ ). Similarly, the heaviest gilts $(146 \mathrm{~kg}$ ) had almost two times difference in BW with the lightest one $(77 \mathrm{~kg})$. The wide ranges of $\mathrm{BF}$ and BW implied the difference in energy reserves and body conditions of gilts in this herd. Due to both traits associated with environmental condition and management regarding to the significant effect of contemporary group $(P<0.0001)$ and their heritability estimates $(0.23 \pm 0.08$ for BF and $0.47 \pm 0.08$ for BW), thus maintaining suitable environment and monitoring nutrient supply and feed intake throughout the herd are needed to optimize body condition of the gilt. The variations for BF and BW in this population should be reduced. The uniformity of replacement gilt would be helpful for breeding herd management and production planning. To optimize gilt's body condition and ensure energy reserve for their production, daily feeding should be done by considering BF of an individual gilt. Providing feed as they need, would help each gilt accumulate fatty tissue properly that would be positive for BW, AFF and WSI. Besides, for economic reasons, it could also prevent an unnecessary feed cost from overfeeding and increased expense for extended management time due to underfeeding that caused thin gilt, delayed puberty, and prolonged non-productive days.

Landrace, originated from the temperate country, has widely been using as the dam line for commercial pig production in Thailand. A high ambient temperature in tropical country might affect well-being and production efficiency of the sow. Even the ancestor of gilts in this population has adapted to the tropical environment over two decades, the environmental condition in the housing still significantly affected fat accumulation, growth, fertility, losing piglet at birth and returning to service of primiparous Landrace sows. During the study period (2010 to 2017), although there was only one degree change in average ambient temperature around the study area $\left(26\right.$ to $\left.27^{\circ} \mathrm{C}\right)$ but the temperature in summer tended to increase by year from $27^{\circ} \mathrm{C}$ in 2011 to $29^{\circ} \mathrm{C}$ in 2017 and reached to $30^{\circ} \mathrm{C}$ in 2016 with the average daily maximum temperature at $37^{\circ} \mathrm{C}$ (Thai Meteorological Department 2019). High temperature in tropical condition especially during summer could lead to heat stress, resulted in decrease feed intake (Quiniou et al. 2000) and depress the de novo fatty acid synthesis in adipose tissues (Wu et al. 2016). However, at 
similar level of feed intake, raising pigs under high ambient temperature could lead to increasing proportion of lipid content of backfat (Kouba et al. 2001) that may result from metabolic response to reduce metabolic heat production from protein metabolism, consequently, more energy was obtained for fat deposition (Le Bellego et al. 2002).

As the current result, gilts born in summer tented to have high BF than gilts born in other seasons, particularly winter (average ambient temperature ranged from 23 to $25^{\circ} \mathrm{C}$ ). Nevertheless, BF of gilt at preselective stage might not depend only environment and management at the beginning of their life, it might be varied by environment and management along their growing phase, feed and feeding program and selection strategy. In this population, gilts born in 2014 and 2015 had a greater BF than gilts born between 2010 and 2013. This result implied that BF might become an important indicator for replacement gilt selection. Then they received more proper feed management to adequate energy reserve to improve their fertility, therefore AFF tended to reduce, paralleled with increased BF in the last two years. The sufficient diet would also support the gilts to accumulate subcutaneous fat in growing phase, especially in winter. They achieved BF at $14 \mathrm{~mm}$ in winter 2014 and 2015 while had BF at $12 \mathrm{~mm}$ in summer of the same year. There was 5 degrees different between summer and winter seasons. High ambient temperature might affect voluntary feed intake of the gilts which is a metabolic response to decrease heat production (Baumgard and Rhoads 2013).

An average BF of Landrace gilts in this population was close to other reports in tropical country such as Landrace gilts in Thailand (Wongsakajornkit and Imboonta 2015) and Landrace, Large White and crossbred gilts in Philippines (Lego and Bondoc 2020) that had BF of 11.80 and $12.29 \mathrm{~mm}$ at 22 weeks old, respectively. Compared to temperate country, our gilts had a lower BF than Landrace $(13.50 \mathrm{~mm}$ for BF at $100 \mathrm{~kg}$ ) and Yorkshire (13.30 mm for BF at $100 \mathrm{~kg}$ ) gilts in China (Hu et al. 2016) and crossbred gilts (13.26 mm for BF at 29 weeks old) in Slovenia (Flisar et al. 2012). Although gilts raised under cold whether seemed to have a higher BF than gilts raised under tropical climate, a high BF (15.60 mm for BF at $77 \mathrm{~kg}$ ) was also performed in Landrace pigs in South Africa (Dube et al. 2011), even in Thailand by Imboonta et al. (2007) who reported $13.90 \mathrm{~mm}$ for BF at 22 weeks old in Landrace gilts. The various BF in different populations might cause by the difference in genetics, breed groups, ages and site at measurement, feed formular, feeding management and environmental conditions (i.e., open-house system or evaporative cooling system) including factors relating feed intake of the pigs.

However, gilts in our population (CV 18\%) had a slightly lower variation of BF than gilts in Philippines (Lego and Bondoc 2020), South Africa (Dube et al. 2011), China (Hu et al. 2016) and Korea (Alam et al. 2021) which had CV ranged from 18.52 to $19.75 \%$ but other Landrace populations in Thailand, they had much higher variation of BF with CV of $25.90 \%$ (Imboonta et al. 2007) and $28.81 \%$ (Wongsakajornkit and Imboonta 2015). The variation of $B F$ in this population was in the range of $B F$ as found in both tropical and temperate countries but more uniformity that implied to the efficiency of feeding program and well management under tropical condition. 
For AFF, tPL and tWSI, their variations highly depended on environmental variation (87.75 to $99.24 \%$ ), indicated the need of monitoring and maintaining suitable environment and management to improve these traits. According to Bertoldo et al. (2009), high ambient temperature could lead to low farrowing rates and delay onset of puberty. But in our results, AFF seemed to not relate to an ambient temperature, its variation would associate with gilt's body condition (BF and BW) and other factors such as heat detection skill, semen quality and farm owner's decision. Thus, the farm owners should focus on feed and feeding program to support growth performance and provide sufficient body fat reserve that is needed for puberty onset. High ambient temperature during summer could also increase the occurrence of stillborn piglets in both tropical (Imboonta et al. 2007) and temperate conditions (Rangstrup-Christensen et al. 2017). Although there was no obvious pattern of PL in the particular season in our research, the highest PL estimates (18.18 $\pm 0.78 \%$ ) was observed in summer 2015 which had an average ambient temperature of $29^{\circ} \mathrm{C}$ and reached to $36^{\circ} \mathrm{C}$ at peak. However, it did not occur in the same pattern every year. Thus, it could be possible that the variation of tPL might not relate to only the ambient temperature at farrowing. Identifying possible risk factors for increased PL in summer 2015 would be helpful to prevent piglet loss in the future.

\section{Association between $\mathrm{BF}$ and production traits}

A high positive genetic correlation between $\mathrm{BF}$ and $\mathrm{BW}(0.70 \pm 0.13)$ and negative genetic correlation between these two traits and AFF ( $-0.42 \pm 0.28$ for BF and AFF, and $-0.62 \pm 0.20$ for BW and AFF) would benefit the genetic improvement program to enhance genetic ability for growth and fertility of the replacement gilt when considering BF at pre-selective stage for selection. Although BF and BW could not be a direct indicator for tWSI due to their correlations but highly positive genetic correlation between AFF and tWSI $(0.78 \pm 0.36)$ revealed the possibility of indirect selection for tWSI by focusing BF or BW of replacement gilt. Therefore, it could be possible to use selection index to improve BF, BW, AFF and tWSI simultaneously. In this population, about $19.35 \%$ of sires, $26.34 \%$ of dams and $25.81 \%$ of sows had a great genetic ability (EBV above the population mean) for BF, BW, AFF and WSI. Those animals should be a target for replacement gilt selection. Selection those sows would make more profit in the next production cycle by improving growth, puberty, and fertility of gilt at the same time. On the contrary, there were $16.94 \%$ of sires, $20.97 \%$ of dams and $17.49 \%$ of sows that needed to be culled due to poor genetic ability (EBV below the population mean) for BF, BW, AFF and WSI.

However, due to the moderate phenotypic correlation between BF and BW $(0.49 \pm 0.03)$, pig producers could use BF record at pre-selective stage as an indicator for growth performance of the replacement gilt that would be useful for routine feed management. Unfortunately, it could not indicate the first productive performance of those gilts due to low phenotypic correlation (closed to zero for BF and TPL and tWSI). A meaningful level of genetic correlation estimate among BF, BW and AFF revealed the need of genetic parameter estimation for setting the target trait and selection plan in genetic improvement program. Considering phenotypic correlation for selection might lead an inappropriate decision to the farm owner which could negatively affect the production efficiency of the sow in the long term. 
At pre-selective stage, the gilts are not fully mature. If the diet is imbalanced or feed intake exceeds the requirement for maintenance, physiological necessity for growth and production, the excess energy will be stored as depot fat (Kyriazakis and Whittemore 2006). Therefore, a thicker BF could imply a heavier BW of gilt at pre-selective stage that allows them passing into the breeding herd, thus, they would produce their first litter early. This result was confirmed by the negative genetic correlation between BF and AFF as the result of BW and AFF. Backfat is the reservoir for several important metabolic hormones associated with puberty attainment of gilts such as leptin and insulin-like growth factor I (Roongsitthichai and Tummaruk 2014). Besides, at the same age, the heavier weight of gilt implied the faster growth rate in the rearing phase and the possibility to be physiologically more mature (Flower 2005). The onset of puberty may be related to the critical body weight and minimum percentage of body fat (Frisch 1984). Thus, gilt that reached the threshold weight or fat percentage early, would show the first estrus and give birth at a young age. Giving first litter early would benefit pig producers by reducing non-productive days and the cost of production. Hence, BF assessment of individual gilt should be practiced routinely for proper feeding suitable to the body condition of the gilts that would help them perform greater fertility.

The genetic correlation between BF and tPL was estimated with high standard error as found between tPL and other production traits. There was a small genetic change in PL when the replacement gilt was selected for BF. Thus, it could be possible to genetically improve both BF and piglet production of the replacement, independently. However, the high standard error of genetic correlation estimates might cause by the limitation of data structure and small dataset, thus, to confirm the association between BF and $\mathrm{PL}$, the genetic correlation should be reinvestigated in a larger dataset.

Regarding to genetic correlation estimates, BF associated with BW more than other production traits. This result might be due to these two traits were measured at similar time. The level of genetic correlation estimates between $\mathrm{BF}$ and production traits seemed to decrease with increased difference in measuring time of the traits. It could imply that BF may indicate body condition and energy reserve of gilt within short span lifetime. Therefore, one possible reason for unclear association between BF at pre-selective stage and tPL might be the long interval between BF measurement ( 28 weeks old) and first farrowing that varied from 20 to 50 weeks, approximately. Naturally, the BF of female pigs can be changed all the time depending on their status in the production cycle. The maternal fatty tissue will be grown in pregnancy as the energy store for fetal development and their own maturity and will be catabolized for mammary development, milk production and rearing their progenies in the lactation period (Kyriazakis and Whittemore 2006). It could be possible that the variation of tPL at first farrowing of sows might more tightly associate with their body conditions at late gestation (days 35 to 100) and parturition which have been known as the critical point for mummified and stillborn piglets (Botaya et al. 2014), or might relate to other risk factors occurred in the duration between BF measurement and first farrowing. The current result was in disagree with Arango et al. (2005) who reported a negative genetic correlation between BF (at 140 or 170 days of age) and number of piglet born dead at first parity of Large White sows (-0.14) and Imboonta et al. (2007) who found a negative genetic correlation between BF (at 22 weeks old) and number of stillborn piglets in first $(-0.04 \pm 0.18)$ and later parities $(-0.22 \pm 0.11)$ in Landrace population. 
The different results of those reports might depend on breed group, data structure, age at BF measurement, characteristics of study trait, statistical model, and environmental condition.

Non-correlation between BF and tWSI might also be due to the difference in measuring time as found in tPL. The tWSI was recorded after weaned that was around 24 to 78 weeks away from BF measurement. The fatty tissue will be accumulated during pregnancy and lost it during lactation (Kyriazakis and Whittemore 2006). Thus, the variations of tWSI in primiparous sows might more closely be correlated with their body conditions at insemination, parturition and post-weaning and amount of BF loss during lactation. As the report of Knecht et al. (2020) in Poland, the significant difference in weaning to service interval was observed between sows with different fatness degree at insemination. Under a well-feeding program, the sows would have an adequate fat store for fetal growth, milk production, rearing their young piglets and replenishing their fatty tissue loss during lactation that would be beneficial for recovering their body to rebreeding condition. Unfortunately, the available data had only BF at pre-selective stage. Promoting pig producers to measure BF of individual female pig as the routine along the production cycle since service, during pregnancy, before parturition and after weaned would provide the supportive information to reveal the association between $\mathrm{BF}$ and production traits that would be useful for improving body condition to support productivity of the breeding sows. Nevertheless, selection emphasis on BF should be optimized. The excess BF of breeding sows could negatively affect their productivity (Roongsitthichai et al. 2010; Zhou et al. 2018). Due to an optimum BF of gilt and sow in each production stage could vary by their genetics and environment, thus it should be investigated in the target population before setting breeding program and feeding management.

However, the association estimates between $\mathrm{BF}$ and production traits are the population parameters that are specific to this Landrace herd. Considering these parameters should concern the population structure, characteristics of the animal, environmental condition, and management. These results would be useful as a case study for commercial Landrace gilts raised under tropical conditions.

\section{Declarations}

\section{Contributions}

TS and SK designed research and contacted the producer. PT gathered and analyzed the dataset. All authors wrote and approved the manuscript.

\section{Acknowledgments}

The author would like to thank a commercial pig farm for providing data of the sow.

\section{Funding}

This research was financially supported by the Royal Golden Jubilee project of the Thailand Research Fund [PHD/0135/2561] and Kasetsart University Research and Development Institute under the development of a Specialized Research Unit in Tropical Animal Genetics [FF(KU)25.64]. 


\section{Conflicts of interest}

The authors have no conflicts of interest to declare.

\section{Availability of data and material}

The datasets generated during and/or analyzed during the current study are available under the permission of the owner of a commercial pig farm, thus they are not publicly available.

\section{Ethics approval}

All female pigs were reared for commercial production with the good agricultural practices for pig farm based on the guidance of National Bureau of Agricultural Commodity and Food Standards. The dataset were extracted from the farm's database that have been gathered as the routine record. Therefore, use of these pigs in research does not require ethical clearance.

\section{References}

1. Alam, M., Chang, H.K., Lee, S.S. and Choi, T.J., 2021. Genetic analysis of major production and reproduction traits of Korean Duroc, Landrace and Yorkshire pigs, Animals, 11, 1321. https://doi.org/10.3390/ani11051321.

2. Arango, J., Misztal, I., Tsuruta, S., Culbertson, M. and Herring, W., 2005. Threshold-linear estimation of genetic parameters for farrowing mortality, litter size, and test performance of Large White sows, Journal of Animal Science, 83(3), 499-506. https://doi.org/10.2527/2005.833499x.

3. Baumgard, L.H. and Rhoads, R.P., 2013. Effects of heat stress on postabsorptive metabolism and energetics, Annual Review of Animal Biosciences, 1, 311-337. https://doi.org/10.1146/annurevanimal-031412-103644.

4. Bečková, R., Daněk, P., Václavková, E. and Rozkot, M., 2005. Influence of growth rate, backfat thickness and meatiness on reproduction efficiency in Landrace gilts, Czech Journal of Animal Science, 50(12), 535-544. https://doi.org/10.17221/4259-CJAS.

5. Bertoldo, M., Grupen, C.G., Thomson, P.C., Evans, G. and Holyoake, P.K., 2009. Identification of sowspecific risk factors for late pregnancy loss during the seasonal infertility period in pigs, Theriogenology, 72, 393-400. https://doi.org/10.1016/j.theriogenology.2009.03.008.

6. Botaya, E.M., Flores, A.G., Moreno, R.B., Sánchez, B.A., Latorre, J.I.C., Díaz, S.A., Martínez, P.P. and Verde, P.M., 2014. Husbandry and Management Practices in Farrowing Units I: Farrowing, (Grupo Asis Biomedia, S.L., Zaragoza, Spain)

7. Dube, B., Mulugeta, S.D., van der Westhuizen, R.R. and Dzama, K., 2011. Non-genetic factors affecting growth performance and carcass characteristics of two South African pig breeds, South African Journal of Animal Science, 41(2), 161-176.

8. Eastwood, L. and Smith, J. Determining the size of finisher pigs, replacement gilts and sows. In: Ontario Ministry of Agriculture, Food and Rural Affairs. 2020. https://files.ontario.ca/omafra- 
determining-the-size-of-pigs-20-061-en-2021-02-08.pdf. Accessed 25 Jun 2021

9. Flisar, T., Malovrh, S., Urankar, J. and Kovač M., 2012. Effect of gilt growth rate and backfat thickness on reproductive performance, Acta Agriculturae Slovenica, Suppl. 3, 199-203.

10. Flower, W.L., 2005. New ideas about gilt development and management, (North Carolina State University, North Carolina)

11. Frisch, R.E., 1984. Body fat, puberty and fertility, Biological Reviews of the Cambridge Philosophical Society, 59(2), 161-188. https://doi.org/10.1111/j.1469-185X.1984.tb00406.x.

12. Gilmour, A.R., Cullis, B.R., Welham, S.J. and Thompson, R., 2000. ASREML Reference Manual, (Hemel Hempstead, UK)

13. Holm, B., Bakken, M., Klemetsdal, G. and Vangen, O., 2004. Genetic correlations between reproduction and production traits in swine, Journal of Animal Science, 82, 3458-3464. https://doi.org/10.2527/2004.82123458x.

14. Houde, A.A., Méthot, S., Murphy, B.D., Bordignon, V. and Palin, M.F., 2010. Relationships between backfat thickness and reproductive efficiency of sows: a two-year trial involving two commercial herds fixing backfat thickness at breeding. Canadian Journal of Animal Science, 90(3), 429-436. https://doi.org/10.4141/CJAS09115.

15. Hu, B., Mo, D.L., Wang, X.Y., Liu, X.H. and Chen, Y.S., 2016. Effects of back fat, growth rate, and age at first mating on Yorkshire and Landrace sow longevity in China, Journal of Integrative Agriculture, 15(12), 2809-2818. https://doi.org/10.1016/S2095-3119(16)61381-3.

16. Imboonta, N., Rydhmer, L. and Tumwasorn, S., 2007. Genetic parameters for reproduction and production traits of Landrace sows in Thailand, Journal of Animal Science, 85(1), 53-59. https://doi.org/10.2527/jas.2005-708.

17. Kemp, B., Da Silva, C.L.A. and Soede, N.M., 2018. Recent advances in pig reproduction: focus on impact of genetic selection for female fertility, Reproduction in Domestic Animals, 53(Suppl. 2), 2836. https://doi.org/10.1111/rda.13264.

18. Knecht, D., Srodon, S. and Czyz, K., 2020. Does the degree of fatness and muscularity determined by ultrasound method affect sows' reproductive performance?, Animals, 10, 794. https://doi.org/10.3390/ani10050794.

19. Kouba, M., Hermier, D. and Le Dividich, J., 2001. Influence of a high ambient temperature on lipid metabolism in the growing pig, Journal of Animal Science, 79, 81-87. https://doi.org/10.2527/2001.79181x.

20. Kraeling, R.R. and Webel, S.K., 2015. Current strategies for reproductive management of gilts and sows in North America, Journal of Animal Science and Biotechnology, 6 , 3. https://doi.org/10.1186/2049-1891-6-3.

21. Kyriazakis, I. and Whittemore, C.T., 2006. Whittemore's Science and Practice of Pig Production, (Blackwell Publishing Ltd, Oxford)

22. Lavery, A., Lawlor, P.G., Magowan, E., Miller, H.M., O’Driscoll, K. and Berry, D.P., 2019. An association analysis of sow parity, live-weight and back-fat depth as indicators of sow productivity, Animal, 
13(3), 622-630. https://doi.org/10.1017/S1751731118001799.

23. Le Bellego, L., van Milgen, J. and Noblet, J., 2002. Effect of high ambient temperature on protein and lipid deposition and energy utilization in growing pigs, Animal Science, 75(1), 85-96. https://doi.org/10.1017/S1357729800052863.

24. Lego, K.A.R. and Bondoc, O.L., 2020. Evaluation of backfat thickness in performance-tested Landrace, Large White and their $F_{1}$ crosses in a local swine breeding farm, Philippine Journal of Veterinary and Animal Sciences, 46(2), 87-95.

25. PIC North America, 2015. Sow \& gilt management manual, (Hendersonville, USA)

26. Quiniou, N., Dubois, S. and Noblet, J., 2000. Voluntary feed intake and feeding behaviour of grouphoused growing pigs are affected by ambient temperature and body weight, Livestock Production Science, 63, 245-253. https://doi.org/10.1016/S0301-6226(99)00135-9.

27. Rangstrup-Christensen, L., Krogh, M.A., Pedersen, L.J. and Sørensen, J.T., 2017. Sow-level risk factors for stillbirth of piglets in organic sow herds, Animal, 11(6), 1078-1083. https://doi.org/10.1017/s1751731116002408.

28. Roongsitthichai, A., Koonjaenak, S. and Tummaruk, P., 2010. Backfat thickness at first insemination affects litter size at birth of the first parity sows, Kasetsart Journal (Natural Science), 44(6), 11281136.

29. Roongsitthichai, A. and Tummaruk, P., 2014. Importance of backfat thickness to reproductive performance in female pigs. The Thai Journal of Veterinary Medicine, 44(2), 171-178.

30. Thai Meteorological Department, 2019. Weather report for 2010 to 2019. (unpublished report, Weather Station Number 327501, Chiang Mai, Thailand).

31. Thiengpimol, P., Koonawootrittriron, S. and Suwanasopee, T., 2020. Genetic parameters for proportion of piglet loss at birth in a Landrace population, Agriculture and Natural Resources, 54, 471-478.

32. Tummaruk, P. and Kesdangsakonwut, S., 2014. Uterine size in replacement gilts associated with age, body weight, growth rate, and reproductive status, Czech Journal of Animal Science, 59, 511-518.

33. Tummaruk, P., Tantasuparuk, W., Techakumphu, M. and Kunavongkrit, A., 2007. Age, body weight and backfat thickness at first observed oestrus in crossbred LandracexYorkshire gilts, seasonal variations and their influence on subsequence reproductive performance, Animal Reproduction Science, 99, 167-181. https://doi.org/10.1016/j.anireprosci.2006.05.004.

34. Wongsakajornkit, N. and Imboonta, N., 2015. Genetic correlations among average daily gain, backfat thickness and sow longevity in Landrace and Yorkshire sows, The Thai Journal of Veterinary Medicine, 45(2), 221-227.

35. Wu, X., Li, Z.Y., Jia, A.F., Su, H.G., Hu, C.H., Zhang, M.H. and Feng, J.H., 2016. Effects of high ambient temperature on lipid metabolism in finishing pigs, Journal of Integrative Agriculture, 15(2), 391-396. https://doi.org/10.1016/S2095-3119(15)61061-9.

36. Zhou, Y., Xu, T., Cai, A., Wu, Y., Wei, H., Jiang, S. and Peng, J., 2018. Excessive backfat of sows at 109 $\mathrm{d}$ of gestation induces lipotoxic placental environment and is associated with declining reproductive 
performance, Journal of Animal Science, 96, 250-257. https://dx.doi.org/10.1093\%2Fjas\%2Fskx041.

\section{Tables}

Table 1 Number of records (N), mean, standard deviation (SD), minimum, maximum and coefficient of variation (CV) for backfat thickness and productive performances

\begin{tabular}{|lllllll|}
\hline Traits $^{\mathrm{a}}$ & $\mathrm{N}$ & Mean & SD & Minimum & Maximum & CV (\%) \\
\hline BF (mm) & 709 & 12.17 & 2.19 & 7 & 20 & 18.00 \\
\hline BW (kg) & 806 & 109.96 & 12.36 & 77 & 146 & 11.24 \\
\hline AFF (day) & 779 & 411.14 & 33.50 & 341 & 500 & 8.15 \\
\hline TB (piglet) & 806 & 10.94 & 3.11 & 2 & 20 & 28.44 \\
\hline NPL (piglet) & 806 & 1.35 & 2.06 & 0 & 14 & 152.01 \\
\hline PL (\%) & 806 & 13.05 & 20.99 & 0 & 100 & 160.83 \\
\hline NWP (piglet) & 777 & 8.89 & 2.98 & 0 & 18 & 33.56 \\
\hline WSI (day) & 707 & 7.59 & 5.47 & 1 & 31 & 72.03 \\
\hline
\end{tabular}

a BF: backfat thickness at 28 weeks old; BW: body weight at 28 weeks old; AFF: age at first farrowing; TB: number of total born piglets; NPL: number of piglet loss at birth; PL: proportion of piglet loss at birth; NWP: number of weaned piglets; WSI: weaning to first service interval.

Table 2 Genetic correlations (above diagonal) and phenotypic correlations (below diagonal) between backfat thickness and production traits of Landrace sows

\begin{tabular}{llllcl} 
Traits $^{\mathrm{a}}$ & $\mathrm{BF}$ & $\mathrm{BW}$ & $\mathrm{AFF}$ & $\mathrm{tPL}$ & tWSI \\
\hline BF & & $0.70 \pm 0.13$ & $-0.42 \pm 0.28$ & $0.40 \pm 1.64$ & $0.00 \pm 0.32$ \\
\hline BW & $0.49 \pm 0.03$ & & $-0.62 \pm 0.20$ & $0.78 \pm 2.60$ & $-0.11 \pm 0.26$ \\
\hline AFF & $-0.20 \pm 0.04$ & $-0.31 \pm 0.03$ & & $-0.23 \pm 1.34$ & $0.78 \pm 0.36$ \\
\hline tPL & $-0.01 \pm 0.04$ & $-0.01 \pm 0.04$ & $0.00 \pm 0.04$ & & $0.31 \pm 1.55$ \\
\hline tWSI & $-0.01 \pm 0.04$ & $-0.05 \pm 0.04$ & $0.01 \pm 0.04$ & $-0.03 \pm 0.04$ &
\end{tabular}

a BF: backfat thickness at 28 weeks old; BW: body weight at 28 weeks old; AFF: age at first farrowing; tPL: transformed proportion of piglet loss at birth; tWSI: transformed weaning to first service interval. 
Values are presented as estimates \pm standard error.

\section{Figures}
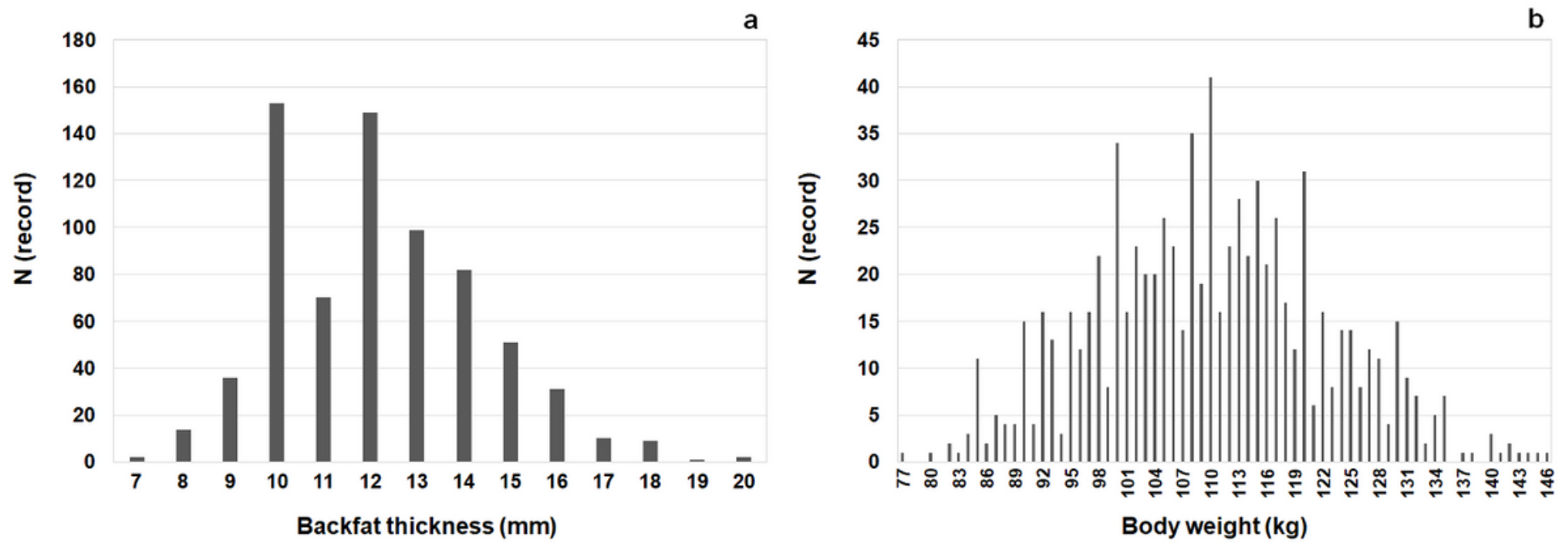

\section{Figure 1}

The distribution of backfat thickness (a) and body weight (b) at 28 weeks old of Landrace gilts

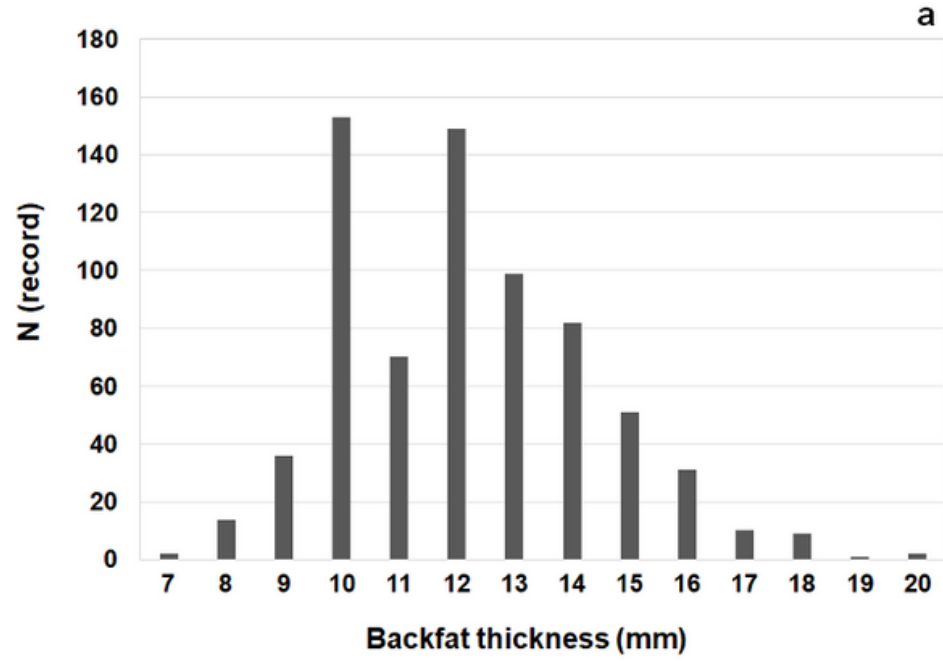

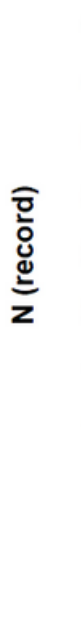

b

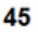

40

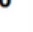

30

25

15

15
10

5

0 i l l l ll స Body weight (kg)

Figure 2

Proportions of additive genetic variance and environmental variance for backfat thickness (BF), body weight (BW), age at first farrowing (AFF), transformed proportion of piglet loss at birth (tPL) and transformed weaning to first service interval (tWSI) in Landrace population. The values in parenthesis show the variance estimates in unit2 
a

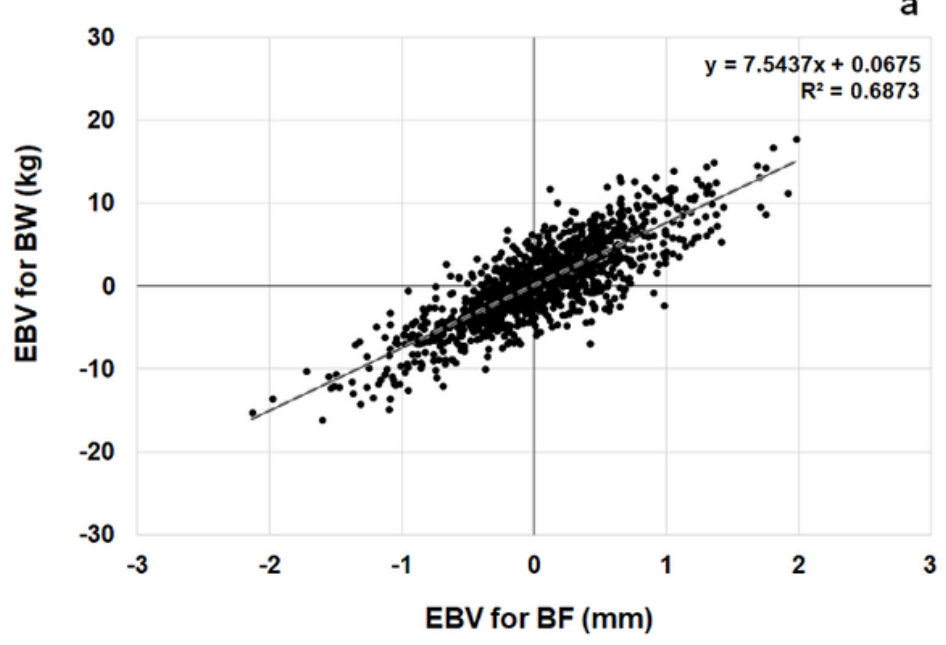

C

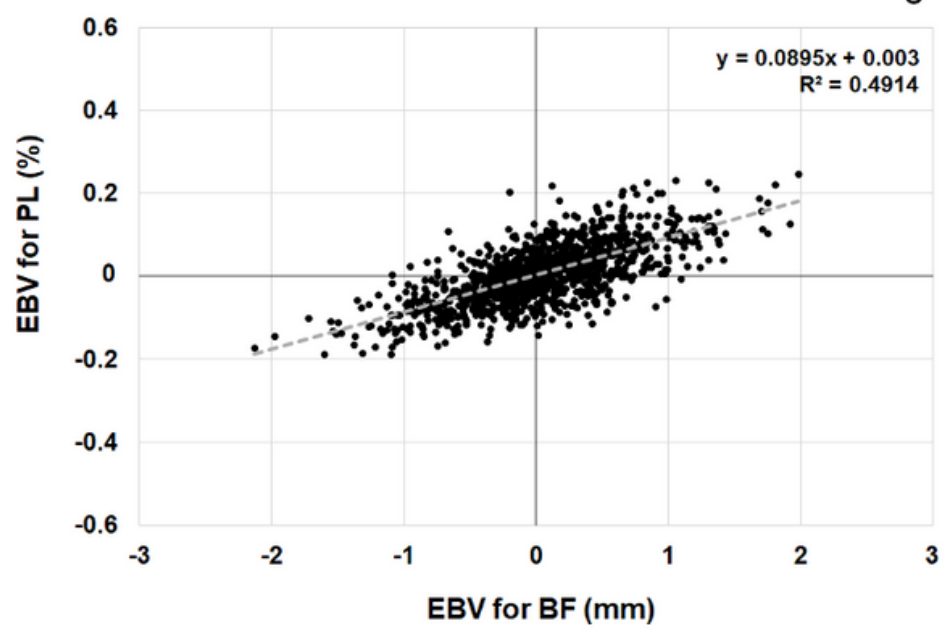

b

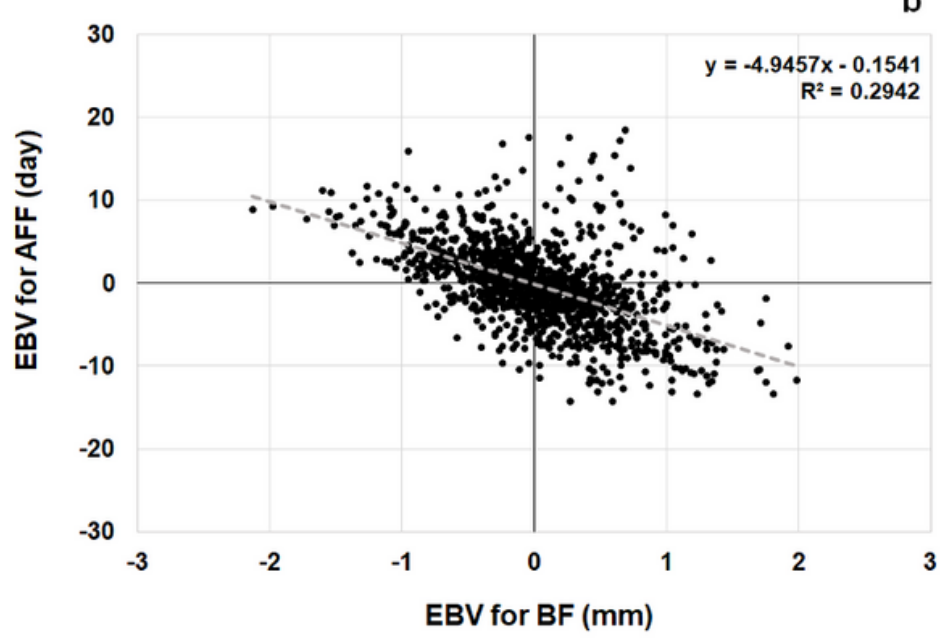

d

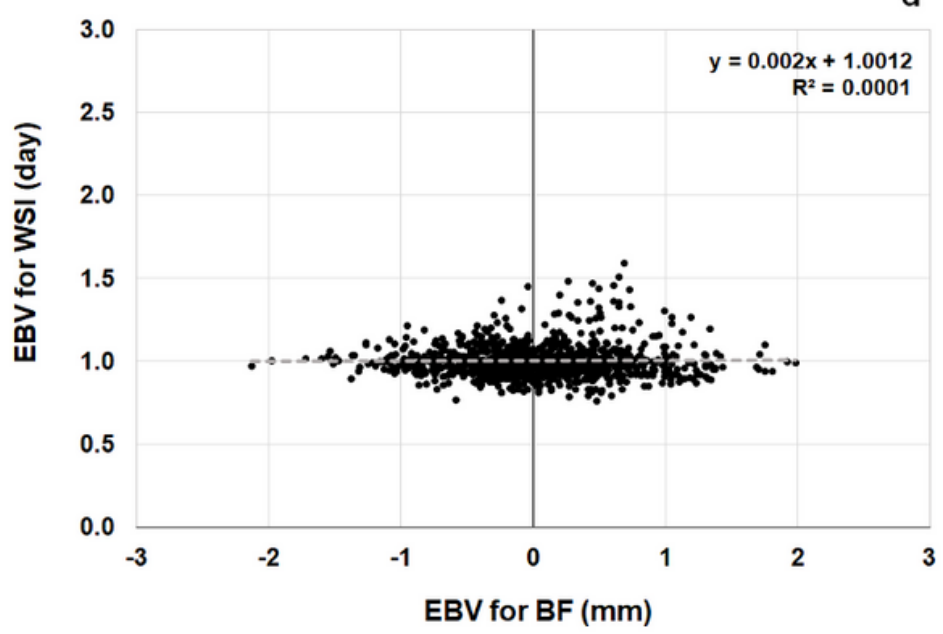

Figure 3

Linear relationships between estimated breeding values (EBVs) for backfat thickness (BF) and body weight (BW; a), age at first farrowing (AFF; b), proportion of piglet loss at birth (PL; $c$ ) and weaning to first service interval (WSI; d) in Landrace population 